\title{
Technical Efficiency of Deposit Taking Savings and Credit Cooperative Societies in Kenya
}

\author{
Carolyne Jebiwott Kimutai \\ Dr. Ambrose Jagongo \\ Dr. Job Omagwa \\ Kenyatta University \\ Kenya
}

\subsection{Abstract}

The deposits taking Savings and Credit Cooperative Societies have continued to play a critical role in Kenya's financial sector in terms of access, savings mobilization and wealth creation. Given the importance of the sector in economic growth, there has been considerable interest in their efficiency. In Kenya, DTS have been reported to have low efficiency, with the average efficiency being less than one. There is limited empirical literature to explain the inefficiency of DTS. In view of this, the study sought to establish the effect of asset quality on efficiency. The study was anchored on Asymmetric Information Theory. The study adopted positivist philosophy and explanatory research design. The target population comprised 110 DTS as at 2017.The study used secondary data that was collected from the audited financial statements for the period 2012-2016.Data was collected using a document review guide. Data Envelopment Analysis methodology was used to generate efficiency scores. The study found that the DTS in Kenya have not achieved efficiency. The study recommends that SASRA should develop a merger policy to encourage the DTS to merge. The management should decrease staff costs and operating expenses by investing in advanced technological innovations in order to increase efficiency.

Keywords: Efficiency, Efficiency, efficiency score, Data Envelopment Analysis

\subsection{Background to the study}

Efficiency is the ratio of actual output to maximum potential output obtainable from a given input level (Marwa \& Aziakpono, 2014). Efficiency indicates how well an organization utilizes its resources to produce goods and services (Coelli, Rao, O'Donnell \& Battese, 2005). Conceptualization of efficiency focuses on inputs, outputs and the rate at which inputs are used to produce the output. Efficiency is improved when fewer inputs are used to produce same amount of outputs or when a fewer or same input produces more outputs of a given quality. If an economic system can use less resources to generate more goods and services then it is said to be more efficient. According to Pi and Timme (1993) efficient firms are able to offer quality services to the customers. They therefore attract more deposits, leading to improved profitability as well as increased the levels of capital. This enables the firm to absorb risks hence attain greater safety. The most important aspect of running a business is how well it is being run (Carr, 2004).

An efficient business will show increased profitability with less input of resources. Any company will be out of business if it does not operate efficiently. As such, therefore, in order to remain on the cutting edge in a very competitive environment, a business must be efficient (Kariuki, 2017). There are considerable debates about what constitutes input and output of financial industry. Berger, Hasan and Zhou (2009) suggest that to analyze efficiency at the bank level the intermediation approach is best suited. However, to determine the efficiency at the branch level, the production approach is appropriate. This is because the main task of management at the branch level is not only to reduce interest expenses on deposits but also reduce total costs. The branch lacks control on financing and investment decisions; it only deals with a large number of customer service processing (Tesfay \& Tesfay 2013).

Stochastic Frontier Analysis (SFA) and Data Envelopment Analysis (DEA) are the most commonly used methods for measuring efficiency (Marwa \& Aziapono 2014; Soboh et al., 2010 Fried et al ., 1993). Each of this methodology has its own weakness and strength and there is no method which is superior than the other (Coelli et al., 2005;Mula,2011).The nature of the data and the context determines the method to be used. If the data set is small nonparametric approach is preffered. In addition, DEA is appropriate when there are multiple input and outputs. If there are less inputs and outputs and the data set is large SFA is used. Various studies on efficiency of financial institutions have been carried out in various countries and contexts using DEA e.g Taylor et al., 2001, Brocket et al.,1997, Kas \& Liv, 2004 Muller, 2011.The latter have used DEA to measure efficiency. The present study used DEA model because of the nature of the data and the context of the study. 
The DEA model developed by Charnes, Cooper and Rhodes (CCR) (1978) and the model developed by Banker Charnes and Cooper (BCC) (1984) are used in this study. BCC and CCR are similar except that BCC does not accommodate variable return to scale and to solve this problem the model includes additional constraints. DEA has a limitation of generating efficiency scores with an upward bias. To solve this problem this study adopted a bootstrap approach proposed by Simar and Wilson (2000).DEA requires specification of inputs and outputs to be made. This decision is key in efficiency modeling. When specifying the inputs and outputs there are three major methods that are used: production, intermediation and asset approach (Nghiem, 2004; Qayyum \& Ahmad, 2006; Moffat, 2008).

In the selection of inputs and outputs, this study used the intermediation approach. This is because DTS are treated as financial intermediaries between the savers and borrowers. They seek to maximize the output that is total loans and other incomes given the input level which is savings and total expenses such that, efficiency equals output over the input. There are two orientations that are very important; the input orientation which is appropriate for policies that have an objective of cost minimization; the output orientation is appropriate for policies that focus on profit maximization (Cooper, Seiford \& Zhu, 2011). When choosing the orientation the focus should be on the quantities of inputs and outputs that managers are able to control (Coelli et al., 2005).In the present study, managers are able to control the inputs than the outputs which are subject to external market forces. Therefore, this study adopted input orientation.

\subsection{Research design}

In this study explanatory non-experimental design was found to be most suitable. Kerlinger and Lee (2000) supports this design especially when the variables to be studied are not manipulated during the research. The choice of this design is justifiable since the study sought to explain factors that cause change and explicitly clarify how some phenomenon operates. This design is further suitable to establishing the causal relationship between study variables against the occurrence of a problem. The study sought give description of certain groups, without manipulation of independent variables and hence the adoption of explanatory non-experimental designs (Were \& Wambua, 2014).

\subsection{Target Population}

According to Borg et al., (2007), the whole set of individuals, events or a thing that the researcher anticipates to investigate is the target population. The target population for the study comprised one hundred and ten DTS societies in Kenya that were in existence from period 2012-2016

\subsection{Empirical Model}

\subsubsection{The Data Envelopment Analysis Model}

Since the study sought to determine the efficiency scores of the DTS, DEA was employed for this purpose. Unlike other parametric model, this methodology doesn't require specification of functional forms since it derives a scalar value as efficiency measure. The output producer in the context of DEA is commonly referred to as a Decision Making Unit (DMU) (Marwa, 2014). For every set of decision making units (DMU's) relative efficiencies are determined. In this analysis, every DMU is allocated their highest possible score of efficiency based on the assessment of inputs and outputs.

In DEA, the efficient threshold is constructed for firms that consume fewer inputs for maximum outputs. Based on this threshold firms close to the threshold are considered efficient while those below are considered inefficient (Ocholla, 2016). The efficiency of each units and each DMU are analysis separately in the DEA Model. Efficiency of DMU is measured by comparing to other DMUs with assumptions that all the DMUs lay below or on extreme threshold (Thanassoulis, 2001).

The DEA model used is shown below:

$$
\text { Maximize } \mathrm{h}_{k}(\mathrm{U}, \mathrm{V})=\frac{\sum_{r=1}^{m} U_{r} Y_{r k}}{\sum_{i=1}^{n} V_{i} X_{i k}}
$$


Subject to $=\frac{\sum_{r=1}^{m} U_{r} Y_{r k}}{\sum_{i=1}^{n} V_{i} X_{i k}} \leq 1$

Where;

$$
U_{r}, V i \geq 0 \quad \mathrm{r}=1,2,3 \ldots \ldots . . \mathrm{i} \quad \mathrm{i}=1,2,3 \ldots
$$

$\mathrm{h}_{k}(U, V)$ is the relative efficiency of $\mathrm{DMU}_{\mathrm{k}}$

$m$ is the No of outputs each DTS using $n$ different inputs

$n$ is the No of inputs used by each DTS to produce $m$ different outputs

$Y_{r k}$ is the amount of the $r^{\text {th }}$ output for the $k^{\text {th }}$ DTS

$X_{i k}$ is the amount of $i^{\text {th }}$ input used by the $k^{\text {th }}$ DTS

$V_{i}$ is the weight to be determined for input $i$

$U_{r}$ is the weights to be determined for output $r$

The solution of the above problem is infinite; to solve the problem, we use the Charnes-Copper (1962) transformation to select an illustrative optimal solution $(U, V)$ for which

$\sum_{i=1}^{m} V_{i} X_{i k}=1$

Hence, a linear programming problem equivalent to the linear functional programming problem (i) to (iii) is derives as follows;

$$
\begin{aligned}
& \operatorname{Maxh}_{\mathrm{k}}(\mathrm{U}, \mathrm{V})=\sum_{r=1}^{S} U_{r} Y_{r k} \\
& \text { Subject to } \sum_{r=1}^{S} U_{r} Y_{r k}-\quad \sum_{r=1}^{S} V_{i} X_{i j} \leq 0 \quad \mathrm{j}=1,2,3 \ldots \mathrm{n} . \\
& \sum_{i=1}^{m} V_{i} X_{l k}=1 \quad \mathrm{i}=1,2,3 \ldots \ldots . . . \\
& \mathrm{U}_{\mathrm{r}} \mathrm{V}_{\mathrm{i}} \geq 0 \quad \text { for } \mathrm{r}=1,2,3 \ldots \ldots \ldots \ldots s
\end{aligned}
$$

Model (iv)-(vii) is the CCR model that is input oriented where maximization is pointed the option of using weights $\mathrm{U}$ and $\mathrm{V}$ with the highest input output ratio. Solving the dual problem above yields optimum results which represent the technical efficiency score for a particular $\mathrm{DMU}_{k}$ when repeated for all DMUs. The relative efficiency hk, of one DMU $k$, is defined as virtual output to virtual input ratio which also a ratio of weighted sum of outputs to weighted sum of inputs. In the model $v_{i}$ and $u_{r}$ indicate significance of each inputs and output and are determined to ensure each DMU has its most efficient. The efficiency is usually achieved when Max $h_{k}=h_{k}^{*}=1$ and at this point DMU is considered efficient. However if $h_{k} *<1$ then the $\mathrm{DMU}_{k}$ is considered not efficient.

\subsection{Research Findings and Discussion}

\subsection{Correlation Analysis (of DEA Inputs and Outputs)}

Table 4.1 presents the results of Pearson's Correlation Analysis between the DEA inputs and outputs used to generate the efficiency scores. 
Table 4.1 Correlation Analysis (of DEA Inputs and Outputs)

\begin{tabular}{|c|c|c|c|c|c|c|c|}
\hline & $\begin{array}{l}\text { Total } \\
\text { loans }\end{array}$ & $\begin{array}{l}\text { Interest } \\
\text { income }\end{array}$ & $\begin{array}{l}\text { Other } \\
\text { income }\end{array}$ & $\begin{array}{l}\text { Staff } \\
\text { cost }\end{array}$ & $\begin{array}{c}\text { Other } \\
\text { expenses }\end{array}$ & $\begin{array}{c}\text { Total } \\
\text { deposit }\end{array}$ & $\begin{array}{c}\text { Interest on } \\
\text { deposit }\end{array}$ \\
\hline Total loans & 1 & & & & & & \\
\hline Interest income & $\begin{array}{l}.891^{* *} \\
.000\end{array}$ & 1 & & & & & \\
\hline Other income & $\begin{array}{l}.694^{* *} \\
.000\end{array}$ & $\begin{array}{l}.664^{* *} \\
.000\end{array}$ & 1 & & & & \\
\hline Staff cost & $\begin{array}{c}.823^{* *} \\
.000\end{array}$ & $\begin{array}{l}.852^{* * *} \\
.000\end{array}$ & $\begin{array}{l}.688^{* * *} \\
.000\end{array}$ & 1 & & & \\
\hline Other expenses & $\begin{array}{l}.716^{* * *} \\
.000\end{array}$ & $\begin{array}{l}.753^{* *} \\
.000\end{array}$ & $\begin{array}{l}.463^{* *} \\
.000\end{array}$ & $\begin{array}{l}.563^{* *} \\
.000\end{array}$ & 1 & & \\
\hline Total deposit & $\begin{array}{l}.980^{* * *} \\
.000\end{array}$ & $\begin{array}{l}.899^{* *} \\
.000\end{array}$ & $\begin{array}{l}.736^{* *} \\
.000\end{array}$ & $\begin{array}{l}.849^{* *} \\
.000\end{array}$ & $\begin{array}{l}.721^{* *} \\
.000\end{array}$ & 1 & \\
\hline $\begin{array}{l}\text { IInterest on } \\
\text { deposit }\end{array}$ & $\begin{array}{c}.618^{* *} \\
.000\end{array}$ & $\begin{array}{c}.638^{* *} \\
.000\end{array}$ & $\begin{array}{l}.541^{* *} \\
.000\end{array}$ & $\begin{array}{l}.572^{* *} \\
.000\end{array}$ & $\begin{array}{c}.412^{* *} \\
.000\end{array}$ & $\begin{array}{c}.639^{* *} \\
.000\end{array}$ & 1 \\
\hline
\end{tabular}

**. Correlation is significant at the 0.01 level (2-tailed).

Source: Study Data, 2018

Table 4.3 identifies correlations among input and output variables. The choice of input and output variables used in DEA is important as explained by Avkiran (1990), Correlations among input and output variables can be used to show the appropriateness of such variables. The correlation between all variables is strong, positive and significant at 0.01 since their $\mathrm{p}$ values are less than 0.01. The recorded high correlation coefficients between DEA inputs and outputs provide support for the appropriateness of the selected inputs and outputs used in the DEA model in this study. The findings corroborate the findings of Tesfay and Tesfay (2013) and Kamau (2011) who found high correlation between the DEA inputs and outputs.

\subsection{Efficiency}

This section presents the technical and scale efficiency of DTS generated from the DEA model and the bias corrected efficiency scores generated after curing the inherent dependency of the scores generated by DEA model.

\subsubsection{Technical and Scale Efficiency}

Table 4.4 summarizes results per year from the DEA model on technical efficiency as measured by constant return to scale (CRSTE) and variable return to scale (VRSTE) and scale efficiency for period 2012 to 2016. If a unit operates under constant return to scale, it indicates that an increase in inputs results in a proportionate increase in the output levels. If a DMU operates under variable return to scale, it indicates that an increase in output does not reflect a proportionate increase in input. This study adopted the variable return to scale because of its assumption which applies to the DTS. However, it is important to calculate the efficiency scores under CRSTE and VRSTE because it helps in explaining the efficiency level.

Table 4.2 Technical and Scale Efficiency

\begin{tabular}{|l|l|l|l|}
\hline YEAR & VRSTE & CRSTE & SCALE \\
\hline 2012 & 0.579 & 0.770 & 0.753 \\
\hline 2013 & 0.766 & 0.833 & 0.916 \\
\hline 2014 & 0.676 & 0.789 & 0.865 \\
\hline 2015 & 0.788 & 0.860 & 0.917 \\
\hline 2016 & 0.803 & 0.868 & 0.927 \\
\hline MEAN & $\mathbf{0 . 7 2 2}$ & $\mathbf{0 . 8 2 4}$ & $\mathbf{0 . 8 7 6}$ \\
\hline
\end{tabular}

Source: Study Data, 2018 
Table 4.4 indicates the technical efficiency as measured under constant and variable returns to scale. On average, the mean efficiency scores for five year period were $72.2 \%$ for VRSTE and $82.4 \%$ for CRSTE reflecting that the firms are inefficient since they have not achieved a score of 1.VRSTE the DTS are required to decrease inputs (Staff cost, other operating expenses, total deposits and interest on deposit) by $27.8 \%$ in order to achieve efficiency or increase outputs (total loans, interest income and other income) by $27.8 \%$ without any additional increase in input to achieve efficiency. The minimum score over the same period were $57.9 \%$ in the year 2012 for VRSTE and $77.0 \%$ for CRSTE, the same year. There has been improvement in efficiency over the five-year period. This can be attributed to regulatory compliance; as more and more DTS becomes compliant the efficiency is improved. This corroborates the study of Mwangi (2014) which found that the average efficiency score for DTS was 0.775 for the period 2009-2013 .Ochola (2016) established that the average efficiency score in Kenya was 0.683 for the period 2011-2013.

Kariuki (2017) observed that industry efficiency score in Kenya was 0.677 for the period 2011-2014.The technical efficiency divergence from the efficient point is $22.8 \%$ and $17.6 \%$ respectively under the VRSTE and CRSTE. This indicates that they could produce the same amount of outputs with approximately $22.8 \%$ fewer resources under variable returns and $17.6 \%$ fewer resources under constant returns than they actually employed. This finding reveals that the overall inefficiency would be attributed to the technical inefficiency rather than scale inefficiency.

\subsubsection{Technical and Scale Efficiency by Size}

Table 4.5 presents the technical efficiency as measured by CRSTE and VRSTE and scale efficiency by size. They are classified into large-tier, medium-tier, and small-tier. According to SASRA (2016), large tier are the ones which have assets worth 5 billion and above. Medium tier have assets between 1 billion and 5 billion. The small tier have assets worth 1 billion and below.

Table 4.3 Technical and Scale Efficiency by Size

\begin{tabular}{|l|l|l|l|l|}
\hline Size & $\begin{array}{l}\text { NUMBER OF } \\
\text { SACCOs }\end{array}$ & VRSTE & CRSTE & SCALE \\
\hline Large-tier DTS & 12 & 0.838 & 0.853 & 0.873 \\
\hline Medium-tier DTS & 40 & 0.712 & 0.850 & 0.991 \\
\hline Small-tier DTS & 45 & 0.616 & 0.769 & 0.765 \\
\hline
\end{tabular}

Source: Study Data, 2018

Table 4.5 presents the mean efficiency of large-tier, Medium-tier, and small-tier as measured by VRSTE as 0.838, 0.712 and 0.616 respectively. This is an indication that the Large-tire are the most efficient, though they have not achieved efficiency; it needs to decrease inputs (staff cost, other operating expenses, total deposits and dividends and interests on deposit) by $16.2 \%$ in order to achieve efficiency. The small-tiers are the least efficient: they are required to decrease their inputs by $38.4 \%$ to achieve efficiency. This corroborates Pessarossi and Weill (2013), who indicates that large firms were more efficient than small firms. In addition, it is evident that the medium-tiers had the highest scale efficiency, followed by the large-tier then the small-tier. This points out that as much as the large tiers are the most efficient they have not exploited their economies of scale.

\subsubsection{Bias Corrected Efficiency Scores}

In the second stage of analysis, efficiency scores are regressed on the financial soundness. Scores generated by DEA model are dependent on each other (Simar \& Wilson 1998). The presence of dependency among the efficiency scores implies that assumption of independence within the sample is violated. To cure this inherent dependency, bootstrap is done. Bootstrap is a procedure of drawing with replacement, producing multiple estimates which can be used for statistical inference. Simar and Wilson (1998) proposed a homogenous bootstrap algorithm. The algorithm based on the bootstrap approach and attributed to Efron (1979), stresses on repeatedly simulating the data generating process and applying the original estimator in each simulated sample. Then the empirical distribution of resampled estimates can be used to generate the bootstrap confidence interval to give the bias corrected efficiency scores. In this study, the efficiency estimation process was implemented in R version 3.1 using the FEAR programme. Table 4.6 below presents a summary of the bias corrected efficiency scores for year 2012 to 2016. 


\section{1 .1}

Table 4.4 Bias Corrected Efficiency Scores

\begin{tabular}{|l|l|l|}
\hline Year & VRSTE & Mean of Bias Corrected VRSTE \\
\hline 2012 & 0.579 & 0.468 \\
\hline 2013 & 0.766 & 0.609 \\
\hline 2014 & 0.676 & 0.523 \\
\hline 2015 & 0.788 & 0.675 \\
\hline 2016 & 0.803 & 0.631 \\
\hline Mean & 0.722 & 0.581 \\
\hline
\end{tabular}

Source: Study Data, 2018

Table 4.6 indicates that the mean of the bias corrected scores are lower than the DEA efficiency scores due to the presence of sampling bias in the DEA scores. Consequently, the study used the Bias Corrected Scores in the second stage of analysis.

\subsection{Summary and Conclusions}

The study found that the mean of DEA inputs and outputs increased over the study period (2012-2016). In addition, the standard deviation of DEA inputs and outputs was slightly higher than the mean, an indication that the data was highly spread.

Furthermore, the study established that the correlation between DEA inputs and outputs was very high; this is an indication that the selected inputs and outputs were appropriate. Lastly, the study found that the DTS had not achieved efficiency though the efficiency level on average had increased over the study period. When classified by size, the large DTS were more efficient than the small ones. The study found that the mean of bias corrected scores was lower than the DEA efficiency scores due to presence of bias.

Most DTS in Kenya are struggling on how to utilize their resources to produce outputs. Small DTS suffer from lack of economies of scale whereas the larger DTS suffer from diseconomies of scale. Large DTS experienced high levels of technical efficiency and struggles with the scale problem. As much as the large DTS are more efficient, they have not exploited their economies of scale. Large DTS are exposed to a larger market where they are forced to compete with commercial banks.

\subsection{Recommendations}

In light of the findings of this study and conclusions drawn thereof, some recommendations to policy and practice are noteworthy. First, the management of DTS ought to be more careful in handling the inputs in producing output. Better usage of resources, can improve technical efficiency. Secondly, the management of DTS ought to work closely with the regulator (SASRA) to create a supporting environment for the small DTS to increase their size and managerial capacity. This can be done by constantly monitoring and supervising, designing an in-service certificate course in management of DTS to improve managerial capacity and offering technical support. Thirdly, management should decrease staff costs and operating expenses by investing in advanced technological innovations in order to increase efficiency. Fifthly, a merger policy for the DTS should be developed so as to encourage the smallest DTS to merge with large DTS. Likewise, the large DTS that are efficient may consider merging with a commercial bank or converting to a micro finance institution in order to increase economies of scale, hence improve efficiency.

\section{References}

Carr, N. G. (2004). Does IT matter. Information technology and the corrosion of competitive advantage, 1.

Coelli, T. J. Rao, D. S. P. O'Donnell, C. J. \& Battese, G. E. (2005). An introduction to efficiency and productivity analysis. Springer Science \& Business Media.

Fried, H.O., Lovell, K.C.A. \& Eeckaut, P.V. (1993). Evaluating the performance of US credit unions. Journal of Banking and Finance, 17:251-265.

Harris, O., Huerta, D., \& Ngo, T. (2013). The impact of TARP on bank efficiency. Journal of International Financial Markets, Institutions and Money, 24, 85-104.

Kamau, A. W. (2011). Intermediation efficiency and productivity of the banking sector in Kenya. Interdisciplinary Journal of Research in Business, 1(9), 12-26.

Kariuki, P. W. O. (2017). Firm Characteristics and Financial Intermediation Efficiency of Deposit Taking Saving and Credit Co-operative Societies in Kenya (Doctoral dissertation, COHRED, JKUAT).

Kariuki, P. W., Muturi, W. M., \& Ngugi, P. K.(2017) Profitability and intermediation efficiency: Evidence from deposit taking saving and credit co-operative societies in Kenya. International Journal of Economics \& Finance (IJEF), 2. 
Kashyap, A. K., Rajan, R., \& Stein, J. C. (2002). Banks as liquidity providers: An explanation for the coexistence of lending and deposit-taking. The Journal of Finance, 57(1), 33-73.

Ke, T. Y., Li, Y., \& Chiu, Y. H. (2011). Analyzing for profit efficiency of banks with undesirable output. African Journal of Business Management, 5(20), 8141.

Kenya, F. S. D. (2013). Central Bank of Kenya (2013). FinAccess National Survey 2013: Profiling developments in financial access and usage in Kenya, Nairobi.

Kerlinger, F. N., \& Lee, H. B. (2000). Foundations of Behavioral Research Thomson Learning. New York.

Marwa, N., \& Aziakpono, M. (2014). Efficiency and profitability of Tanzanian saving and credit cooperatives: who is a star?.

Ochola, P.(2016) A two-stage study on efficiency of saving and credit cooperative societies in kenya International Journal of Economics Commerce and Management

Pi, L. \& Timme, S. G. (1993). Corporate control and bank efficiency. Journal of Banking \& Finance, 17(2), 515-530.

Taylor, R.A. (2001). Credit unions and economic efficiency. Rivista Internazionale di Scienzes Economicale e Commerciali, 24:239-47.

Tesfay, H. \& Tesfay, A. (2013). Relative efficiency of rural saving and credit cooperatives: An application of data envelopment analysis. International Journal of Cooperative Studies, 2(1), 16-25.

Were, M., \& Wambua, J. (2014). What factors drive interest rate spread of commercial banks? Empirical evidence from Kenya. Review of Development Finance, 4(2), 73-82. 